University of Wollongong

Research Online

Faculty of Engineering and Information

Faculty of Engineering and Information

Sciences - Papers: Part B

Sciences

2018

Calculation analysis of yaw bearings with a hardened raceway

Peiyu He

Nanjing Tech University

Rongjing Hong

Nanjing Tech University

Hua Wang

Nanjing Tech University

$\mathrm{Xu} \mathrm{Ji}$

Shaanxi University of Science and Technology

Cheng Lu

University of Wollongong, chenglu@uow.edu.au

Follow this and additional works at: https://ro.uow.edu.au/eispapers1

Part of the Engineering Commons, and the Science and Technology Studies Commons

Research Online is the open access institutional repository for the University of Wollongong. For further information contact the UOW Library: research-pubs@uow.edu.au 


\title{
Calculation analysis of yaw bearings with a hardened raceway
}

\author{
Abstract \\ The yaw bearing is a key support structure of wind turbines and is often exposed to substantial complex \\ loads that cause damage and fatigue failure. Raceway surfaces accommodate high contact stress and \\ require a hardening treatment. The hardened depth has a great influence on both the carrying capacity \\ and fatigue life. We establish a whole finite element model of a yaw bearing and use non-linear springs \\ instead of a ball to obtain the maximum contact load. The results of a strain gauge experiment and an \\ empirical formula are compared to verify the spring model results. A local finite element model of a ball \\ and raceway with different hardened depths is established to analyse the stress distribution and fatigue \\ life. The raceway is divided into a hardened layer, transition layer, and core layer. An indentation \\ experiment verifies the raceway model with different layers. The stress results are compared with Hertz \\ contact theory, and the fatigue life results are compared with yaw bearing fatigue life theory. The \\ influence of different hardened depths on the stress and lifetime of yaw bearings is analysed.

\section{Disciplines} \\ Engineering | Science and Technology Studies

\section{Publication Details} \\ He, P., Hong, R., Wang, H., Ji, X. \& Lu, C. (2018). Calculation analysis of yaw bearings with a hardened \\ raceway. International Journal of Mechanical Sciences, 144 540-552.
}




\title{
Hardened raceway calculation analysis of yaw bearing
}

\author{
Peiyu $\mathrm{He}^{1}$, Rongjing Hong ${ }^{1}$, Hua Wang ${ }^{1}$, Cheng $\mathrm{Lu}^{2}$
}

1-School of Mechanical and Power Engineering, Nanjing Tech University, Nanjing

$$
\text { 211816, China }
$$

2- School of Mechanical, Materials and Mechatronic Engineering, University of

Wollongong, NSW 2522, Australia

Abstract: Yaw bearing is a key support structure of wind turbine, and is often exposed to substantial complex loads that cause it to be prone to damage and fatigue failure. Raceway surfaces bear high contact stress and require hardened treatment. The hardened depth has a great influence on both carrying capacity and fatigue life. We establish a whole finite element model of yaw bearing and use non-linear springs instead of a ball to obtain the maximum contact load. Strain gauge experiment and empirical formula are compared to verify spring model results. A local finite element of ball and raceway with different hardened depths is established to analyze the stress distribution and fatigue life. Raceway is divided into a hardened layer, a transition layer, and a core layer. Indentation experiment verifies the raceway model with different layers. The stress results compare with Hertz contact theory, and the fatigue life results compare with yaw bearing fatigue life theory. The influence of different hardened depth on the stress and life of yaw bearing is analyzed.

Key word: yaw bearing; hardened raceway; stress analysis; life analysis.

\begin{tabular}{|llll}
\hline \multicolumn{2}{l}{ Nomenclature } & & \\
$\alpha\left(^{\circ}\right)$ & Contact angle & $L_{n m}$ & ANSI/ABMA standard \\
& & & modified rating life \\
$a_{1}$ & Life modification factor & & \\
& for reliability (reliability & $M(\mathrm{~N} . \mathrm{mm})$ & Overturning moment
\end{tabular}


$90 \%)$

Life modification factor

for bearing steel or $\quad N_{f} \quad$ Cycles

material

Life modification factor

for lubrication

Ball number

Life modification factor

for a flexible supporting $n$ Index

structure

Basic dynamic axial load

rating

$n^{\prime \prime} \quad$ Index

Groove curvature center

of the inner ring lower $r(\mathrm{~mm})$

Groove radius of raceway

curvature

Groove curvature center

of the inner ring upper $P_{e a}(\mathrm{~N})$

Dynamic equivalent axial

raceway

load rating

Groove curvature center

of the outer ring lower $Q_{(\mathrm{N}) \quad \text { Contact load }}$

raceway

Groove curvature center

of the outer ring upper $Q_{\max }(\mathrm{N}) \quad$ Maximum load

raceway

Ductility index $\quad T_{1} \quad$ Theoretical calculation of

raceway stress cycles

$D_{L}(\mathrm{~mm}) \quad$ Raceway center diameter $\quad z(\mathrm{~mm}) \quad$ Raceway hardened depth

$D_{i} \quad(\mathrm{~mm}) \quad$ Outer ring inner diameter $\quad \alpha \quad$ Index

$D_{O} \quad(\mathrm{~mm}) \quad$ Outer ring outer diameter $\quad \beta \quad$ Index 


\begin{tabular}{|c|c|c|c|}
\hline$D_{w} \quad(\mathrm{~mm})$ & Ball diameter & $\delta \quad(\mathrm{mm})$ & Deformation \\
\hline$d_{O} \quad(\mathrm{~mm})$ & Inner ring outer diameter & $\delta_{q} \quad(\mathrm{~mm})$ & Indentation depth \\
\hline$d_{i}(\mathrm{~mm})$ & Inner ring inner diameter & $\sigma_{0.2} \quad(\mathrm{MPa})$ & Yield strength \\
\hline$E_{1}(\mathrm{MPa})$ & Ball elastic modulus & $\sigma_{a}(\mathrm{MPa})$ & Stress amplitude \\
\hline$E_{2}(\mathrm{MPa})$ & Raceway elastic modulus & $\sigma_{f}^{\prime}$ & $\begin{array}{l}\text { Fatigue strength } \\
\text { coefficient }\end{array}$ \\
\hline$f$ & Groove radius coefficient & $\sigma_{v}(\mathrm{MPa})$ & Equivalent stress \\
\hline$F_{a}(\mathrm{~N})$ & Axial load & $\sigma_{v p e r m}(\mathrm{MPa})$ & $\begin{array}{l}\text { Allowable equivalent } \\
\text { stress }\end{array}$ \\
\hline$F_{r}(\mathrm{~N})$ & Radial load & $\mu_{1}$ & Ball Poisson ratio \\
\hline$H(\mathrm{~mm})$ & Outer ring height & $\mu_{2}$ & Raceway Poisson ratio \\
\hline$H_{1}(\mathrm{~mm})$ & Total height & $\sum \rho$ & The sum of curvature \\
\hline$i$ & Rolling element row & $\Delta r_{\max }$ & Shear strain amplitude \\
\hline$h(\mathrm{~mm})$ & Inner ring height & $\Delta \varepsilon_{n}$ & Principal strain amplitude \\
\hline$K$ & Elastic deformation index & $\varepsilon_{a}(\mathrm{~mm})$ & Strain amplitude \\
\hline$K^{\prime}(\mathrm{MPa})$ & Index & $\varepsilon_{e}(\mathrm{~mm})$ & Elastic strain \\
\hline$k$ & Ball constant & $\varepsilon_{p} \quad(\mathrm{~mm})$ & Plastic strain \\
\hline$L_{10}$ & $\begin{array}{l}\text { Slewing bearing basic } \\
\text { rating }\end{array}$ & $\varepsilon_{f}^{\prime}$ & $\begin{array}{l}\text { Fatigue extension } \\
\text { coefficient }\end{array}$ \\
\hline
\end{tabular}

\section{Introduction}

Wind energy is a resource-rich, renewable green energy. With the world's new energy development and utilization, wind power industry has become an important strategy in energy-saving emission reduction and environment protection. Yaw bearing and pitch bearing are important parts of a wind turbine, as shown in Fig. 1. 
Among them, yaw bearing is a key support structure of the wind turbine. It is installed in the wind turbine nacelle base to make the cabin rotate around the tower, and to timely adjust the fan's windward angle to get maximum power output. Substantial complex loads, hundreds of tons of cabin, an installation location up to tens of meters, inconvenient disassembly and expensive maintenance demand high reliability and long life of a yaw bearing. It has a large size and contains the inner ring, outer ring, ball, cage and other components, as shown in Fig. 2.

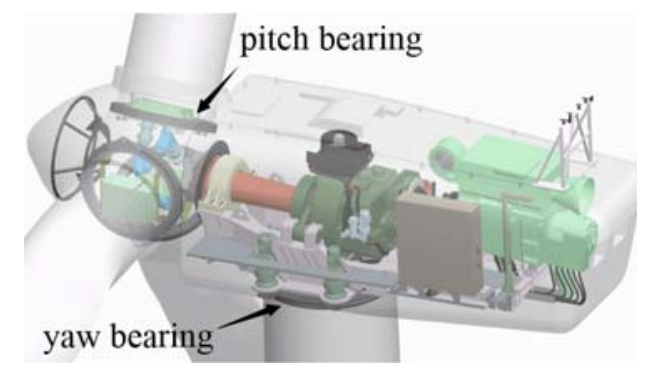

Fig. 1 Yaw and pitch slewing bearings in a wind turbine

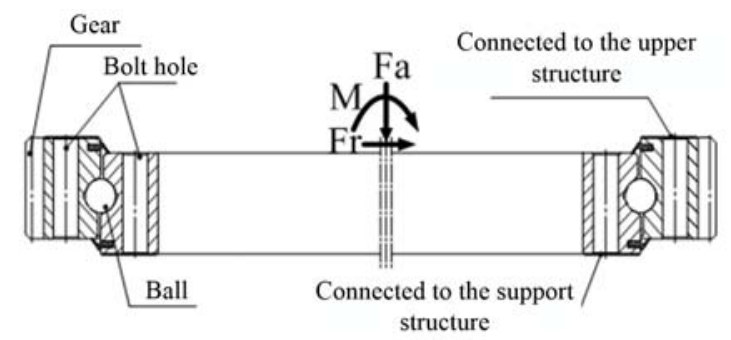

Fig. 2 Single row four-point contact ball yaw bearing structure

For yaw bearing as large wind power bearing, a finite element method can effectively reduce test costs and shorten development time. Many researchers use a finite element method to study the yaw bearing. Springs instead of rolling elements in the overall calculation model have great advantages in fast calculation and easy convergence. Hardened raceway in a local finite element model greatly influences the stress distribution and fatigue life of a yaw bearing. Wang et al. [1] established single row and double rows four-point contact ball finite element models to analyze pitch bearing carrying capacity. The model considered the effects of clearance, raceway curvature, and initial contact angle. Guanci et al. [2] took a four-point contact ball bearing as an example to research the influence of ball size and hardened raceway on fatigue life. Stress life, strain life, and international standard methods were used to 
analyze the fatigue life. Jon et al. [3] proposed a superelement-based FE model to research the slewing bearing in wind turbine generators. It can significantly reduce the computational cost at a high computational accuracy. The ball was replaced with a rigid shell element, rigid beam elements, and traction only spring elements in the finite element calculation. Göncza et al. [4] established a three-row roller slewing bearing finite element model with hardened raceway to evaluate static carrying capacity. The model took the effects of arbitrary roller geometry, raceway's material into account. Results show that the cylindrical roller, logarithmical roller and partially crown roller are very different in carrying capacity. Gao et al. [5] used non-linear springs instead of a ball to calculate the load distribution of a single-row ball slewing bearing. Aguirrebeitia et al. [6] used the theoretical calculation combined with the finite element model considering the preload to analyze the slewing bearing static carrying capacity of wind turbine generators. The ball was replaced with a rigid shell element, rigid beam elements, and traction only spring elements in the finite element calculation. Göncz et al. [7] presented an assessment of the rolling contact fatigue life of an induction hardened raceway. Their experiment obtained 42CrMo high contact fatigue parameters and verified the fatigue life. Kania et al. [8] used superelements (nonlinear truss elements) instead of a ball to calculate the slewing bearing carrying capacity. They considered the influence of ring flexibility, bolts, and rolling element. Gao et al. [9] proposed rolling contact fatigue reliability methods combined with Lundberg-Palmgren theory and ISO 281. Contact load, contact geometry parameters, and material parameters were taken into account. Göncz et al. [10] calculated the static carrying capacity of three-row roller slewing bearings combined with ring flexibility, non-parallel ring displacement, clearance, and hardened raceway. Potočnik et al. [11] proposed a procedure to calculate the fatigue life of a double-row ball slewing bearing. It described the geometric parameters as vectors to consider irregularly shaped bearings. Lai et al. [12] analyzed hardened depth and carrying capacity. The plastic compression and subsurface destruction were verified by standard contact fatigue tests. Kunc et al. [13] researched the bearing capacity with hardened raceway and experimented with the low cycle carrying capacity. Olave and 
Sagartzazu [14] established a finite element model of a four-point contact ball slewing bearing in order to analyze the load distribution considering ring geometry effects. Their results are consistent with the theoretical calculation. Daidié and Chaib [15] established a slewing bearing finite element model to analyze the load distribution and contact angle changes. Using springs instead of a ball, they evaluated the change in contact angle. Experiment validated the model effectiveness. Göncz and Drobne [16] established the finite element model of a three-row roller slewing bearing in order to analyze the load and stress distributions. Using the stress-life method, they obtained the slewing bearing working life. Göncz and Potočnik [17] used ABAQUS to establish a two-dimensional contact fatigue crack propagation model. Expansion of the initial contact fatigue crack on the slewing bearing surface was simulated. Results show that the analytical results are of some reliability and will be used more frequently in subsequent analytical applications. Zaretsky et al. [18] used the Monte-Carlo method to test fatigue life of a rolling bearing with a certain fixed speed. The bearing service life under different bearing steels was compared. Potočnik et al. [19] studied the fatigue life of double-row ball slewing bearing, as well as the influence of ring deformation and hardened layer depth.

Critical stress-strain and fatigue life area of the raceway with hardened layer are observed several millimeters below the raceway contact position. Yaw bearing diameter can be several meters. If the whole model is refined, the grids number will reach tens of millions. Hundreds of contact pairs can easily lead to non-convergence for the actual analysis. Based on this reason, using non-linear springs instead of the ball leads to the maximum contact load. The relationship between ball and raceway under external load is studied based on Hertz contact theory. Calculation results are compared with the empirical calculation equation. A local finite element model of the ball and raceway is established to observe the influence of different hardened depths on the stress and life of yaw bearing. 


\section{Raceway finite element model with different layers}

\subsection{Theoretical depth calculation of hardened layer}

Contact areas of yaw bearing ball and raceway have high contact stress. If raceway surface is not heat treated, rings easily produce core damage. To improve the quality and extend service life, raceways must be hardened. In this paper, 010.40.1000 type yaw bearing from JB/T2300-2011[19] is studied. The structure is shown in Fig. 3, and the parameters shown in Table. 1 . The axial load $F_{a}$ is $5.25 \times 10^{5} \mathrm{~N}$, the radial $\operatorname{load} F_{r} \quad 1.75 \times 10^{5} \mathrm{~N}$, and the overturning moment $M 4.5 \times 10^{8} \mathrm{~N} \cdot \mathrm{mm}$.

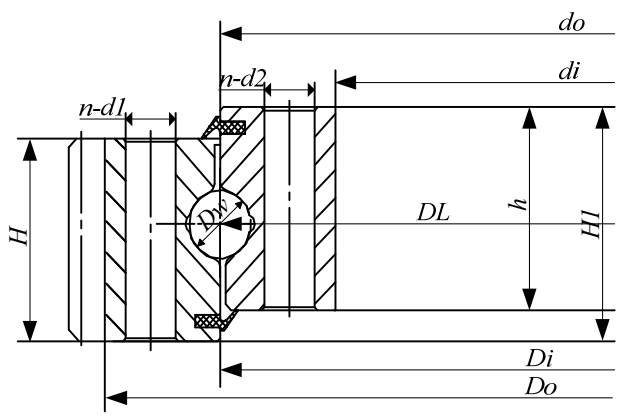

Fig. 3 Structure of a single row four-contact ball yaw bearing

Table. 1 Specification parameters of single row four-contact ball yaw bearing

\begin{tabular}{|c|c|c|c|}
\hline Parameter & Size & Parameter & Size \\
\hline $\begin{array}{c}\text { Outer ring outer diameter } D_{O} \\
(\mathrm{~mm})\end{array}$ & 1122 & Total height $H_{1}(\mathrm{~mm})$ & 100 \\
\hline $\begin{array}{l}\text { Outer ring inner diameter } D_{i} \\
(\mathrm{~mm})\end{array}$ & 998 & Ball diameter $D_{w}(\mathrm{~mm})$ & 40 \\
\hline $\begin{array}{c}\text { Inner ring outer diameter } d_{O} \\
(\mathrm{~mm})\end{array}$ & 1001 & Groove radius coefficient $f$ & 0.525 \\
\hline Inner ring inner diameter $d_{i}(\mathrm{~mm})$ & 878 & $\begin{array}{c}\text { Groove radius of curvature } r \\
(\mathrm{~mm})\end{array}$ & 21 \\
\hline Raceway center diameter $D_{L}$ & 1000 & Contact angle $\alpha \quad\left({ }^{\circ}\right)$ & $45^{\circ}$ \\
\hline
\end{tabular}




\begin{tabular}{|c|c|c|c|}
\hline$(\mathrm{mm})$ & & & \\
\hline Outer ring height $H(\mathrm{~mm})$ & 90 & Ball number $n$ & 64 \\
\hline Inner ring height $h(\mathrm{~mm})$ & 90 & & \\
\hline
\end{tabular}

Yaw bearing has a different core allowable equivalent stress $\sigma_{v p e r m}$ according to different materials. $42 \mathrm{CrMo}$ yield strength $\sigma_{0.2}$ is $635 \mathrm{MPa}$. The relationship between the core allowable equivalent stress and the yield strength is shown in equation (1):

$$
\sigma_{\text {vperm }}=k \sigma_{0.2}
$$

where $k$ is a constant for the ball $(0.75)$.

According to Fig. 4 and Hertz contact theory, the relationship between equivalent stress $\sigma_{v}$ and the raceway hardened depth $z$ is obtained. The hardened layer depth is from the raceway surface to the area where the hardness is greater than $52.5 \mathrm{HRC}$. The transition depth from $52.5 \mathrm{HRC}$ hardness area to the core is $10 \%$ of the hardened layer depth as shown in Fig. 8. When the equivalent stress $\sigma_{v}$ and the allowable equivalent stress $\sigma_{v p e r m}$ are the same, the depth is $110 \%$ of the minimum value of the hardened layer.

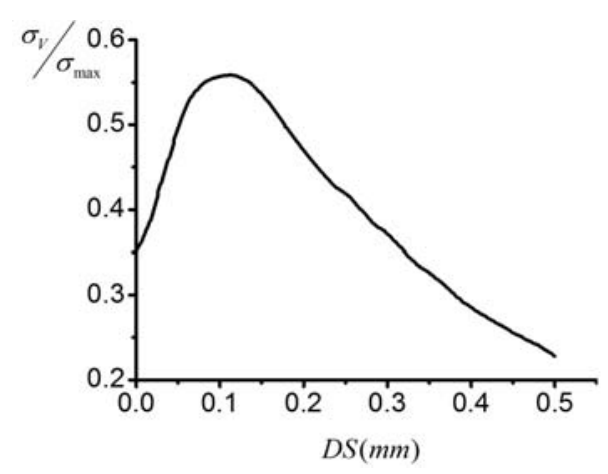

Fig. 4 The relationship between $\sigma_{v}$ and $z$ 


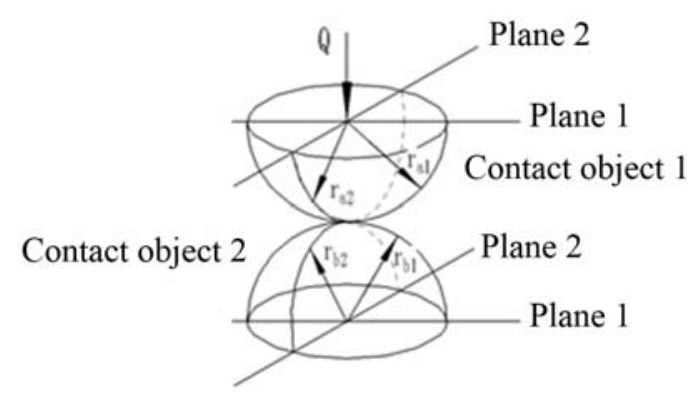

Fig.5 Hertz theory contact diagram

According to a U.S. National Renewable Energy Laboratory wind turbine yaw bearing fatigue life theory calculation "Wind turbine design guideline DG03: yaw and pitch rolling bearing life" [20], the empirical calculation equation of the maximum contact load is shown in equation (2):

$$
Q_{\max }=\left(\frac{2 F_{r}}{n \cos \alpha}+\frac{F_{a}}{n \sin \alpha}+\frac{4 M}{D n \sin \alpha}\right)
$$

Hertz contact theory is a classical method used to obtain contact stress and deformation $[22,23]$. Fig. 5 shows a pair of contact spheres. The radii are $r_{a 1}$ and $r_{b 1}$ in plane 1. The radii are $r_{a 2}$ and $r_{b 2}$ in plane 2. The long half-axis $a$, the short half-axis $b$ and maximum contact stress $\sigma_{\max }$ of the contact ellipse are as follows:

$$
\begin{gathered}
a=\alpha\left[\frac{3 Q}{2 \sum \rho}\left(\frac{1-\mu_{1}^{2}}{E_{1}}+\frac{1-\mu_{2}^{2}}{E_{2}}\right)\right]^{\frac{1}{3}} \\
b=\beta\left[\frac{3 Q}{2 \sum \rho}\left(\frac{1-\mu_{1}^{2}}{E_{1}}+\frac{1-\mu_{2}^{2}}{E_{2}}\right)\right]^{\frac{1}{3}} \\
\sigma_{\max }=\frac{3 Q}{2 \pi a b} \\
\sum \rho=\rho_{11}+\rho_{12}+\rho_{21}+\rho_{22} \\
F(\rho)=\frac{\left|\rho_{11}-\rho_{12}\right|+\left|\rho_{21}-\rho_{22}\right|}{\sum \rho}
\end{gathered}
$$

where $\mu_{1}$ is the ball Poisson ratio, $\mu_{2}$ is the raceway Poisson ratio, $E_{1}$ is the ball elastic modulus, $E_{2}$ is the raceway elastic modulus, $Q_{\max }$ is the maximum contact 
load, $\sum \rho$ is the sum of curvature, $\alpha$ and $\beta$ are obtained from a table [27].

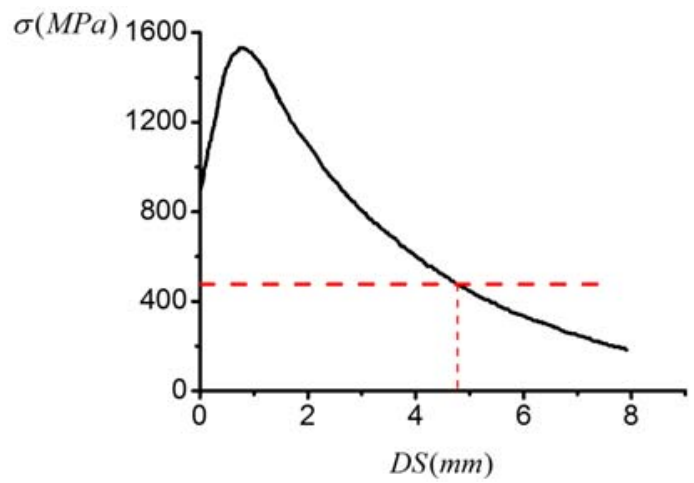

Fig. 6 Determination curve of the yaw bearing hardened layer depth

The short half axis $b$ is $1.0828 \mathrm{~mm}$ and the maximum contact stress $\sigma_{\max }$ is 3292.7 MPa from equations (3), (4) and (5). Using $\sigma_{v p e r m}$ and $\sigma_{\max }$ yields the relationship curve shown in Fig. 6 [24]. The depth $z_{p}$ of the intersection of the allowable equivalent stress and the actual equivalent stress is $4.75 \mathrm{~mm}$. The minimum hardened layer depth $D S$ is $4.3182 \mathrm{~mm}$.

The hardened layer depth is provided in JB/T2300-2011 as follows: $D_{w}>40 \sim 50 \mathrm{~mm}, \quad D S \geq 4.0 \mathrm{~mm}$. The theoretical calculation of hardened layer depth is bigger than the regulation (JB/T2300-2011). Hardened raceway depths of DS $3 \mathrm{~mm}$, $4 \mathrm{~mm}, 5 \mathrm{~mm}$ and $6 \mathrm{~mm}$ are used to analyze different depth effect on stress and fatigue life for subsequent analysis.

\subsection{Verification of raceway finite element model with different layers}

Ball and raceway contact form of yaw bearing is point contact. Contact experiment between the ball and a hardened plate specimen is performed to measure the indentation depth on the plate specimen surface. The relationship between indentation depth and contact stress is established by linear regression analysis. An allowable contact stress of $42 \mathrm{CrMo}$ is obtained [26]. The sample material and heat treatment are the same as the yaw bearing. In the test, the upper anvil of the test press 
applies the pressure. The ball is indented on the plate specimen as shown in Fig. 7. The press pressure is changed during the test to obtain indentation under varying pressure. Indentation depths are measured using a Talyrond 364 cylindrical instrument.

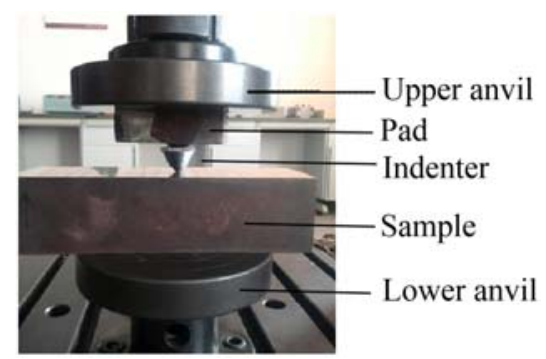

Fig. 7 Experimental diagram

The mathematical relationship between contact stress $\sigma_{\max }$ and ratio of indentation depth to ball diameter $\frac{\delta_{q}}{D_{w}}$ is shown in equation (8) [26]:

$$
\frac{\delta_{q}}{D_{w}}=k \sigma_{\max }^{b}
$$

where $\sigma_{\max }$ is the maximum contact stress, $\delta_{q}$ is the indentation depth, $D_{w}$ is the ball diameter, $k$ is a constant obtained from the data, and $b$ is an index obtained from the data.

Equation (8) makes the following transform:

$$
y=\lg \left(\delta_{q} / D_{w}\right)^{\prime} x=\sigma_{\max }, a=\lg k
$$

Equation (8) changes into a straight line regression equation.

$$
y=a+b x
$$

The indentation test data of Fig. 11 is inserted into equation (11), and a correlation coefficient $r$ obtained [27]. There are 36 sets of indentation data.

$$
r=\frac{\sum_{i=1}^{n}\left(x_{i}-\bar{x}\right)\left(y_{i}-\bar{y}\right) \quad}{\sqrt{\sum_{i=1}^{n}\left(x_{i}-\bar{x}\right)^{2}} \sqrt{\sum_{i=1}^{n}\left(y_{i}-\bar{y}\right)^{2}}} \quad, \frac{1}{n} \sum_{1}^{n} x_{i}, \bar{y}=\frac{1}{n} \sum_{1}^{n} y_{i}
$$

A correlation coefficient $r(0.9609)$ is obtained using MATLAB. The correlation 
coefficient $r$ obtained using equation (13) is larger than the $r(0.424)$ in the correlation coefficient significance test table [27].Therefore, the linear regression equation (11) is valid.

Equation (12) is calculated by substituting the indentation depth test results converting the power function curve into a nonlinear regression curve.

$$
\frac{\delta_{q}}{D_{w}}=10^{-19.6918} \sigma_{\max }^{4.2881}
$$

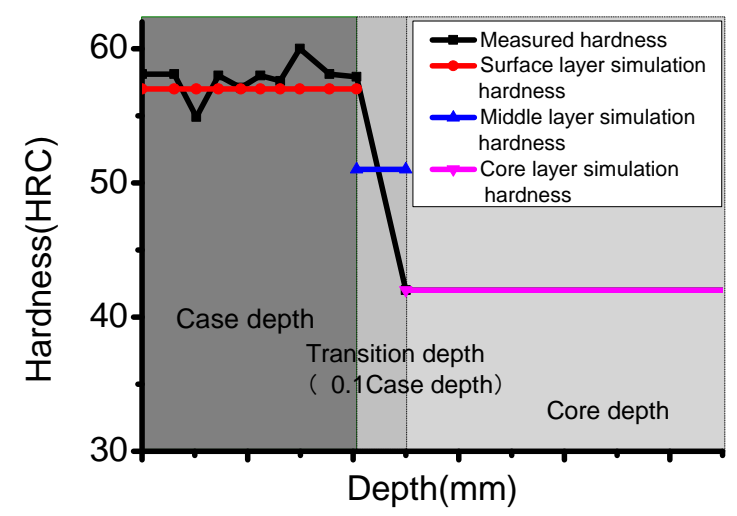

Fig. 8 Raceway hardness of different layers

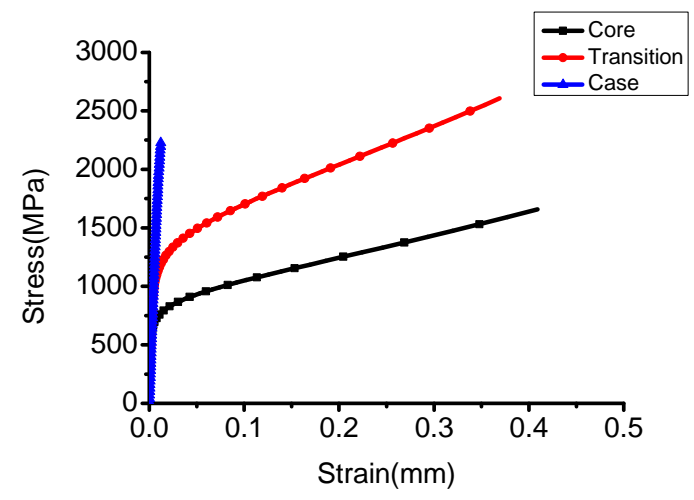

Fig. 9 Stress-strain curves of various raceway layers

The yaw bearing raceway surface hardness is $57-62 \mathrm{HRC}$, and the hardness is gradually reduced from the raceway to the area of $42 \mathrm{HRC}$, as shown in Fig. 8. A finite element model the same as the indentation test is established in this paper. The plate specimen is divided into a case layer, transition layer and core layer as shown in Fig.10. The Ramberg-Osgood equation of equation (13) is combined with the material parameter shown in Table. 2 in order to calculate the stress and strain. Table.2 parameters are obtained on the basis of the available experimental data by averaging or by linear regression of the values available from the literature [28, 29, 30]. 


$$
\varepsilon_{a}=\varepsilon_{e}+\varepsilon_{p}=\frac{\sigma_{a}}{E}+\left(\frac{\sigma_{a}}{K^{\prime}}\right)^{1 / n^{\prime}}
$$

where $\varepsilon_{a}$ is the strain amplitude $(\mathrm{mm}), \varepsilon_{e}$ the elastic strain $(\mathrm{mm}), \varepsilon_{p}$ the plastic strain $(\mathrm{mm}), \sigma_{a}$ the stress amplitude $(\mathrm{MPa}), E$ the modulus of elasticity (MPa), $K^{\prime}$ the cyclic strength coefficient, and $n^{\prime}$ the cyclic strain hardening exponent.

Table. 2 Material parameters of each layer

\begin{tabular}{|c|c|c|c|c|c|}
\hline & Hardness(HRC) & $E(\mathrm{MPa})$ & $v$ & $K^{\prime}(\mathrm{MPa})$ & $n^{\prime}$ \\
\hline Core & 42 & 207000 & 0.3 & 1173 & 0.0932 \\
\hline Transition & 51 & 211000 & 0.3 & 1963 & 0.1054 \\
\hline Case & 57 & 212000 & 0.3 & 5808 & 0.1550 \\
\hline
\end{tabular}

Fig. 10 Indentation test finite element model

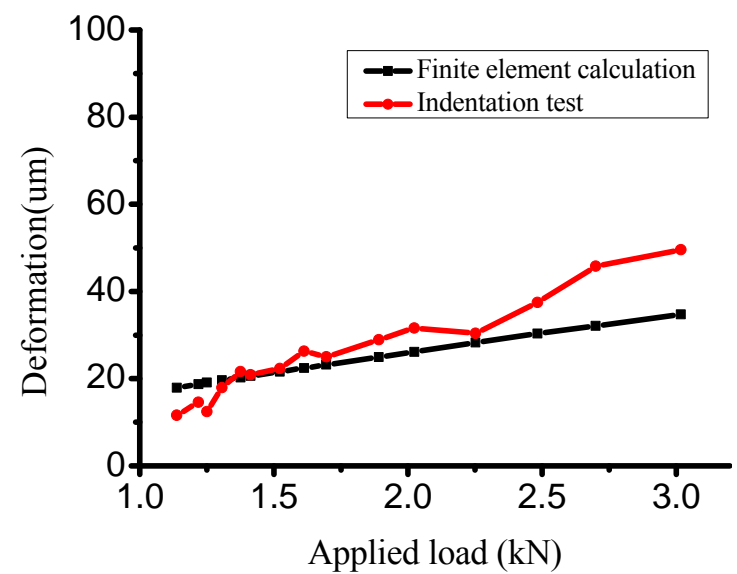

Fig. 11 Comparison of experimental and finite element results 
When $\frac{\delta_{q}}{D_{w}}$ is $0.01 \%$, the allowable contact stress is $4564 \mathrm{MPa}$. When the ball deformation is one ten-thousandth of the diameter, the maximum contact stress is $4200 \mathrm{MPa}$, according to Hertz contact theory [20]. The contact stress error is $8.6 \%$ between the indentation test and Hertz theory, and the validity of the indentation experiment is proved. Fig. 11 shows that the deformation obtained by finite element calculation increases uniformly with load, and the fluctuation deformation obtained by indentation test increases with load. In a hardened treatment plate specimen, it is difficult to ensure the same hardness and hardened depth of each point on the specimen surface. An indentation experiment selects a straight line on the specimen surface and evenly selects the load point. The indentation depth is obtained by the proportional load on the load point. The raceway layer finite element model can be used in the follow-up raceway stress and life analysis according to the plate machining error, treatment error, and measurement error.

\section{Finite element model of non-linear springs}

\subsection{Establishment of non-linear spring model}

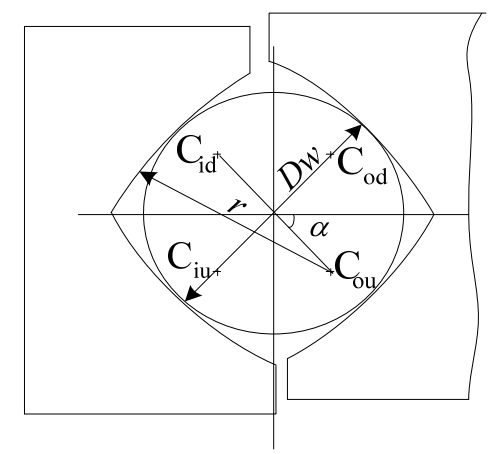

Fig. 12 Yaw bearing cross section

A four-point contact ball yaw bearing raceway is composed of four circular raceways as shown in Fig.12. The raceway cross section gap is zero. $C_{i u}$ is the groove curvature center of the inner ring upper raceway. $C_{i d}$ is the groove curvature 
center of the inner ring lower raceway. $C_{o u}$ is the groove curvature center of the outer ring upper raceway. $C_{o d}$ is the groove curvature center of the outer ring lower raceway. The structure parameters are shown in Table. 1. The contact and deformation relationship between ball and raceway is described by equation (14) based on Hertz contact theory [31]:

$$
Q=K \delta^{n^{n}}
$$

where $Q$ is the contact load, $K$ the elastic deformation index, $\delta$ the deformation, $n^{\prime \prime}$ is 1.5 when the rolling element is a ball. $K$ is $1.74 \times 10^{6} \mathrm{~N} / \mathrm{mm}$ according to the calculation method [25].

Equation (14) shows that the contact load and deformation between raceway and ball is a non-linear relationship. Therefore, non-nonlinear springs can be used to simulate the contact behavior between raceway and ball. As shown in Fig. 13, the stress-deformation characteristics of non-linear springs are consistent with those of the ball. The raceway and ball only cause contact deformation under pressure load, and the non-linear spring needs to define the compression characteristics as shown in Fig.14. The whole non-linear spring finite element model of the yaw bearing is shown in Fig.15. The spring number and position are consistent with the ball number and position. Two contact points of ball and raceway are selected to create a spring.
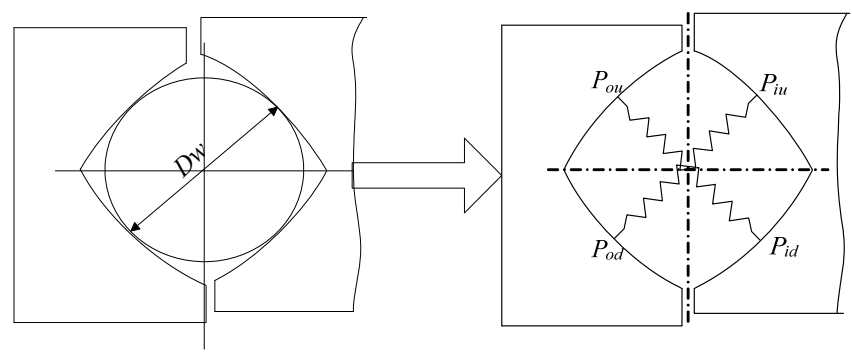

Fig. 13 Nonlinear spring instead of a ball 


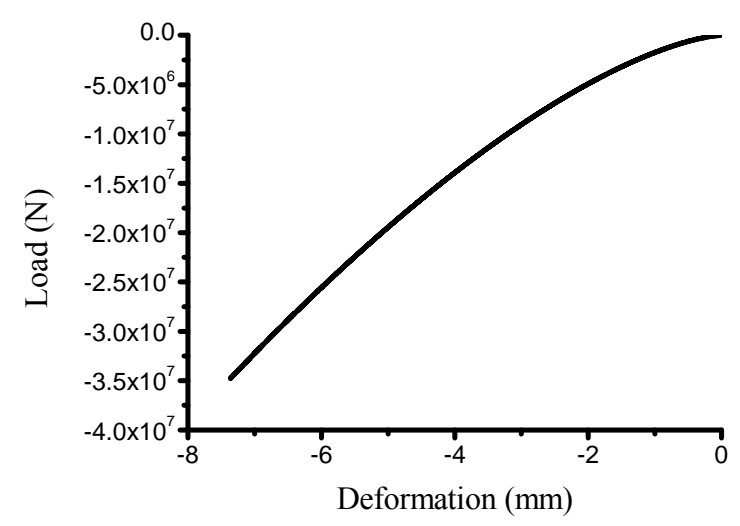

Fig. 14 Load-deformation characteristic of a nonlinear spring

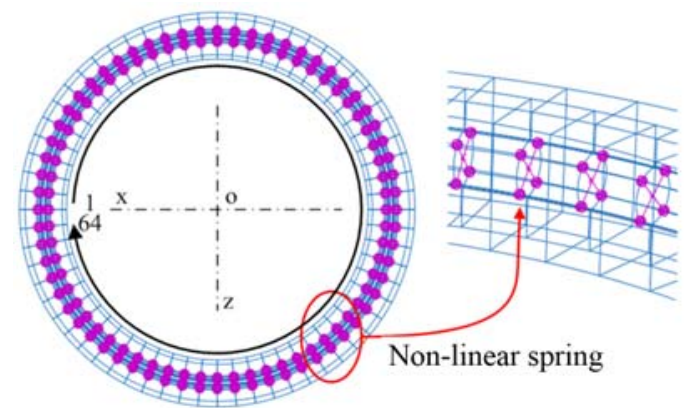

Fig. 15 Nonlinear spring model

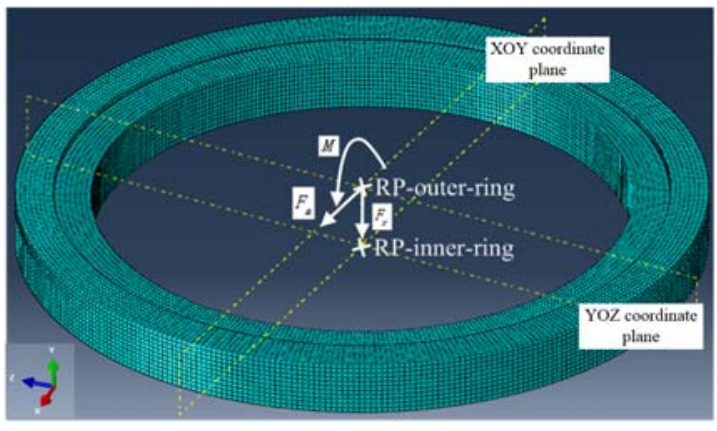

Fig. 16 Loads applied to the yaw bearing

The reference point Rp-inner-ring and Rp-outer-ring are established in the inner and outer ring geometric center. The Rp-inner-ring is a kinematic coupling on the surface between the inner ring and the mounting base. The Rp-outer-ring is a kinematic coupling on the surface between the outer ring and the upper swivel mechanism. Rp-inner-ring is a full constraint. The Rp-outer-ring releases Z-direction rotation degrees of freedom, as well as $\mathrm{X}$-direction and Y-direction translation degrees of freedom. Other degrees of freedom are restrained. The load is applied in the Rp-outer-ring as shown in Fig.16. 


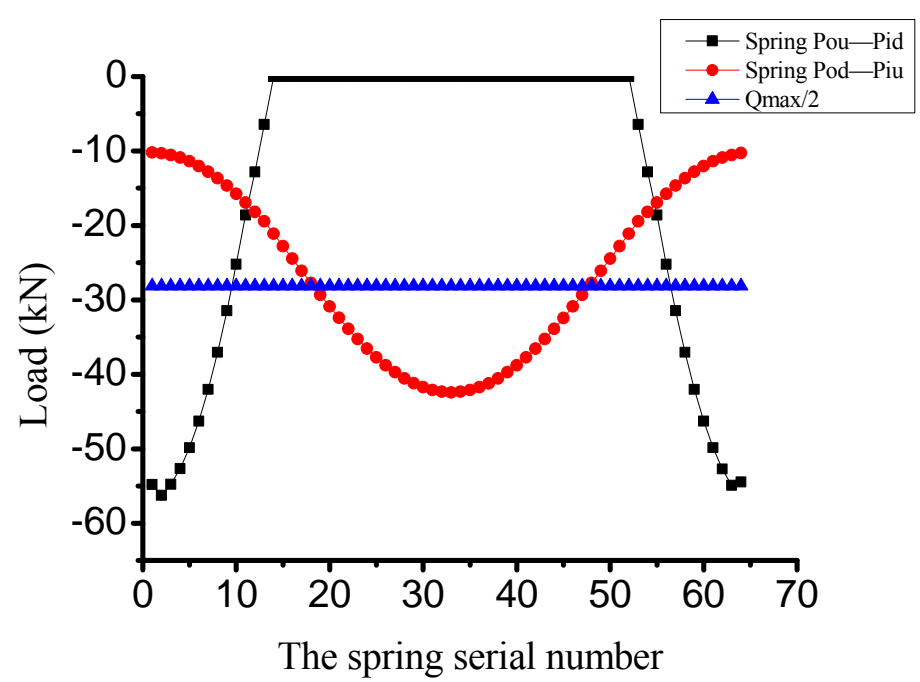

Fig. 17 Yaw bearing load hierarchies

The load distribution extracted from each spring is shown in Fig.17; the maximum contact load is $56260 \mathrm{~N}$, and the negative sign indicates pressure. The raceway load is divided into light, middle, and heavy loads. $\frac{Q_{\max }}{2}$ is chosen as a dividing line to roughly determine yaw bearing heavy load and light load areas, according to finite element static load analysis.

Table. 3 Comparison of maximal contact load obtained by different models

\begin{tabular}{ccc}
\hline Model & $Q_{\max }$ & Error \\
\hline Non-linear spring model & $56260 \mathrm{~N}$ & 0 \\
The empirical equation & $59110 \mathrm{~N}$ & $5 \%$ \\
\hline
\end{tabular}

A contact load of $59110 \mathrm{~N}$ is obtained from the empirical calculation equation (2). Comparison results are shown in Table. 3 and the error is only $5 \%$, which verifies the correction of the non-linear spring finite element model.

\subsection{Experiment verification of the non-linear spring model}

To ensure the yaw bearing carrying capacity and to verify the aforesaid theoretical analysis of finite element simulation, a strain gauge experiment is performed. The whole yaw bearing test stand is mainly composed of a yaw bearing assembly system, a hydraulic loading system, a drive system, a measurement system, and a control system. The mechanical structure is shown in Fig. 18 and the physical 
structure is shown in Fig. 19.

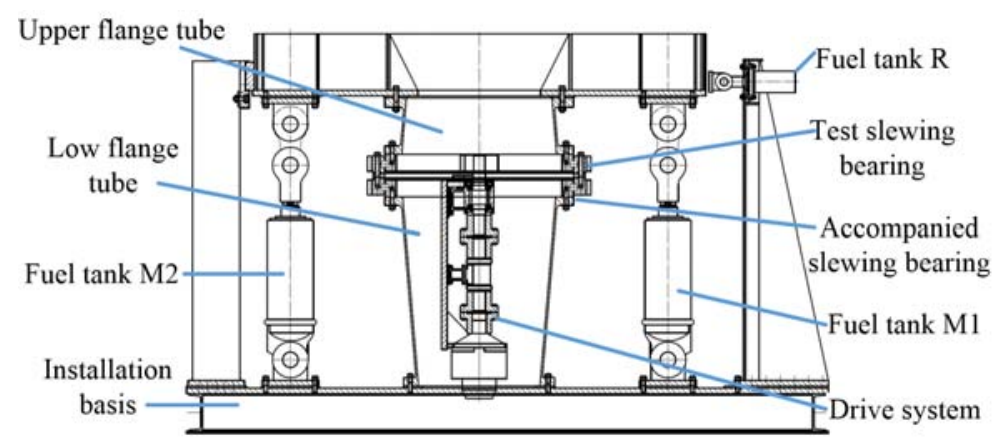

Fig. 18 Schematic diagram of the yaw bearing test stand structure

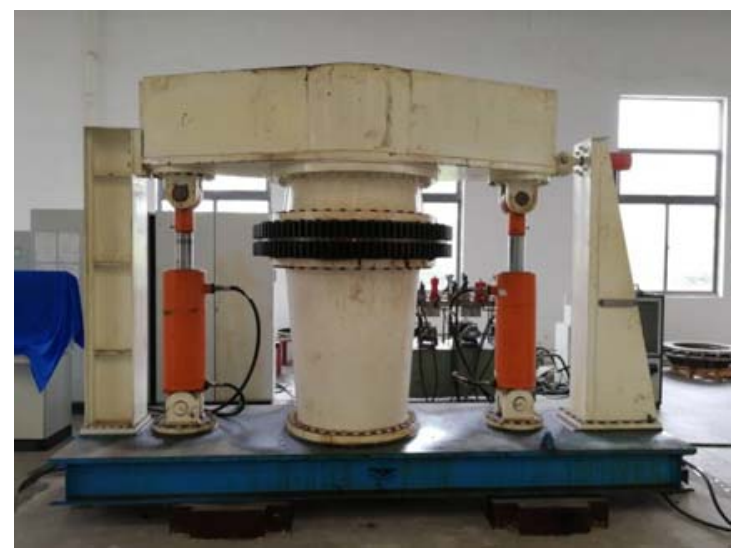

Fig. 19 Yaw bearing test stand

The test stand can achieve different specifications of yaw bearing carrying capacity according to the design requirements. To ensure reliability of the experiment data, the yaw bearing on the test stand should be as realistic as possible. The experimental yaw bearing is the same and installed "face-to-face" or "back-to-back". Bolts are used to connect the flange with the yaw bearing. Different flange specifications are changed to achieve different yaw bearings.

A stress circle of the yaw bearing raceway can't be directly obtained. The strain measurement method is used to measure the stress. Strain gauges are installed on the inner ring circumference and measured under external load. The main monitoring equipment is a DH3815N-3 static strain test system. To meet the experimental measurement requirements, strain gauges are arranged evenly along the inside of the circumference. The deformation direction of the strain gauge is consistent with the axial direction of the yaw bearing, and the temperature compensated. The measurement point layout is shown in Fig. 20, and the actual layout diagram is shown in Fig. 21. 


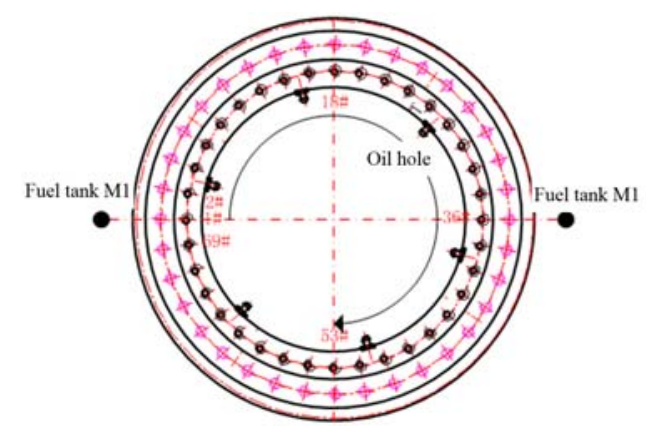

Fig. 20 Strain gauge measuring points layout diagram

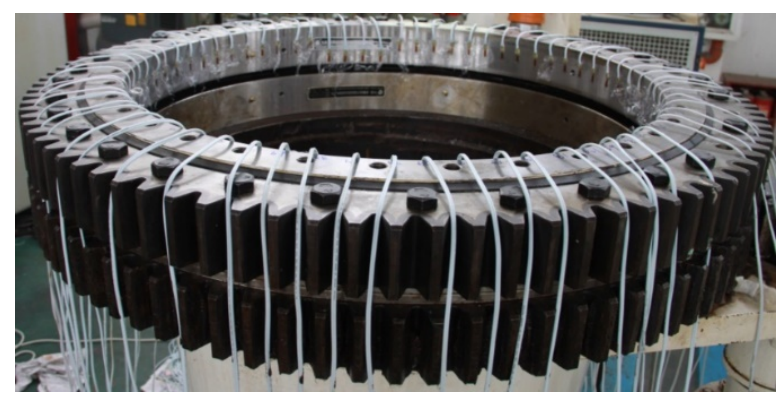

Fig. 21 Actual layout diagram of strain gauge measuring points

Fig. 22 shows that variation trends of stress distribution of the yaw bearing are basically the same under different loads. Strain gauges close to the M1 side are under pressure, and No. $23 \sim 43$ strain gauges measured stress values are negative. Strain gauges close to the M2 side are under tensile load, and No. $1 \sim 16$ and 57 69 strain gauges measured stress value are positive. The interaction area of M1 and M2 hydraulic cylinders (No. 17 22 and No. 44 56) should theoretically be lightly loaded, however, the stress value of the region has a greater variability, due to interference of the mechanical structure( installation of the uneven surface of the base, bolt preload, and other factors). The contact load is extracted from the spring finite element model according to the strain position of the strain gauge. Table.4 summaries the applied load of the different stages.

Table. 4 Static load level

\begin{tabular}{ccc}
\hline Load lever & $\begin{array}{c}\text { Fuel tank M1 } \\
\text { load (MPa) }\end{array}$ & $\begin{array}{c}\text { Fuel tank M2 } \\
\text { load (MPa) }\end{array}$ \\
\hline Initial stage value & 0.0 & 0.0 \\
Primary stage load & 2.0 & 0.7 \\
Secondary stage load & 3.5 & 1.8
\end{tabular}




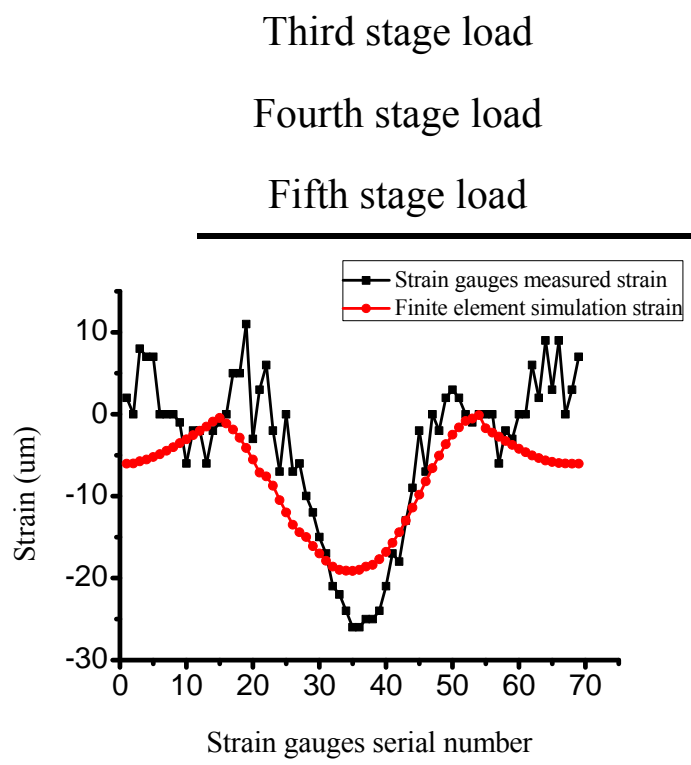

(a)

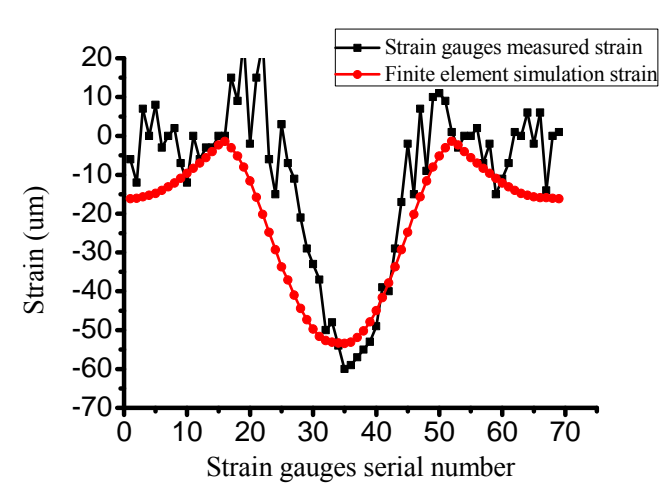

(b)
$5.0 \quad 2.5$

$7.0 \quad 2.5$

$9.0 \quad 5.0$

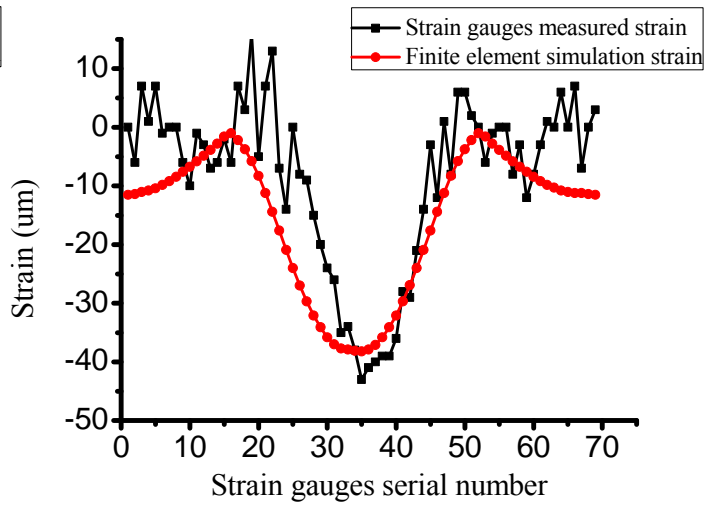

(b)

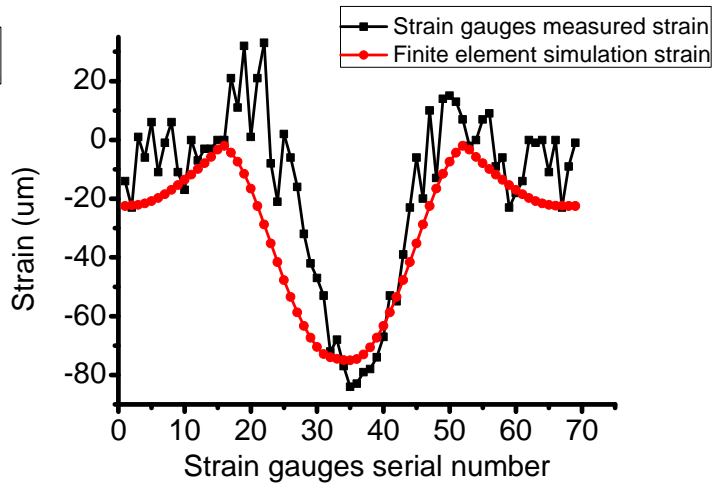

(d)

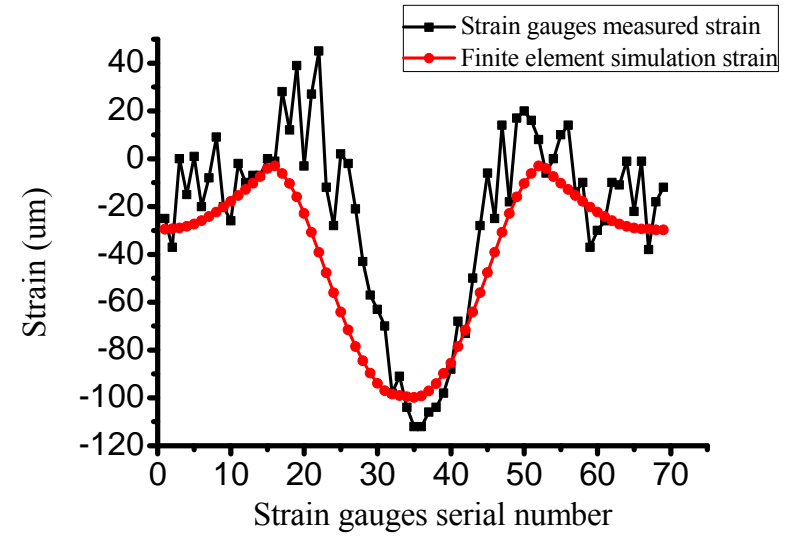

(e)

Fig. 22 Results of the strain gauge and spring finite element model (a) Primary stage load; (b) Secondary stage load; (c) Third stage load ;(d) Fourth stage load ;(e) Fifth stage load

Results show that the experiment load distribution and the theoretical analysis 
are different, but the light load and heavy load distribution are consistent. The reliability of the spring finite element analysis results are proved.

\section{Local solid finite element model of ball and raceway}

A local solid finite element model of ball and raceway is established and the maximum contact is obtained using a non-linear spring finite element model. The focus of this paper is stress and life on the hardened raceway, and the model is simplified as shown in Fig. 23. The dotted line is the cross-sectional shape of ball and raceway, and the solid line is a simplified model. A half finite model is established. The minimum grid size below the raceway is $0.1 \mathrm{~mm}$. The finite element type is C3D8R, the element shape is hexahedron and the contact algorithm is Advancing front. When the contact position grid size is half of the short half axis, the influence of the grid size on the calculation can be ignored [4]. The short half-axis of the Hertz contact theory is $1.0828 \mathrm{~mm}$ from equation (4). The raceway bottom of the simplified model is fixed constraint and the raceway XOY plane is symmetrically constrained. The XOY plane and XOZ plane of the ball are symmetrically constrained. The ball is coupled with the RP-1, which releases the Y-direction degree-of-freedom and constrains the other degrees-of-freedom. The load is applied in RP-1 as shown in Fig. 24.

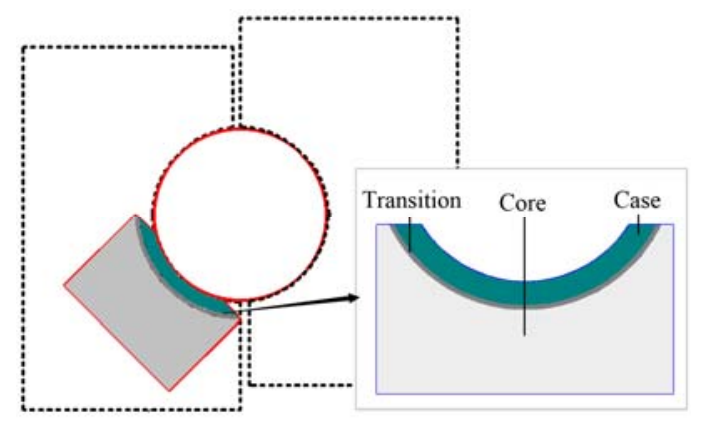

Fig. 23 A simplified model of ball and raceway 


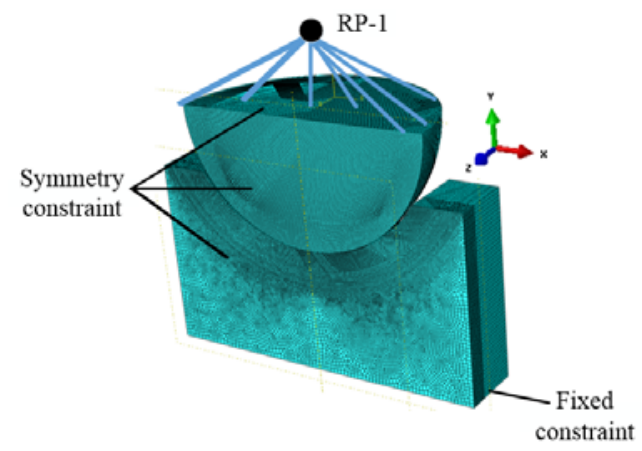

Fig. 24 Local solid finite element model of ball and raceway

\subsection{Stress analysis of local solid finite element model}

Fig. 25 shows that the contact area is approximately elliptical and the maximum contact stress is $3126 \mathrm{MPa}$ when the hardened depth is $4 \mathrm{~mm}$. Contact stress distributions of other hardened depths are the same as Fig. 25 and the maximum contact stress is different, as shown in Table. 5. Contact stress from Hertz contact theory is bigger than the finite element model and the error is small, which indicates the correctness of the local solid finite element model. Hertz contact theory makes some assumptions and simplification that produce safe results. The finite element analysis is more in line with actual working conditions that influence factors (the friction coefficient, the contact angle, the ring deformation, etc.). The finite element method is more accurate than the theoretical calculation of the yaw bearing.

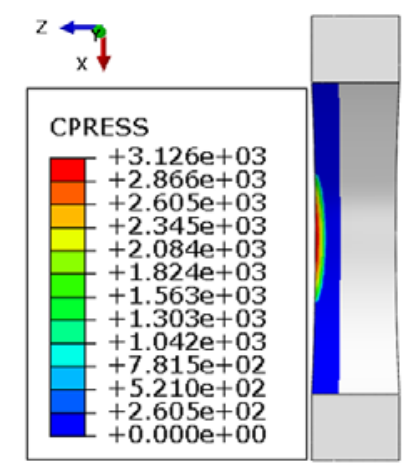

Fig. 25 Contact stress of the hardened depth $4 \mathrm{~mm}$

Table. 5 Contact stress of the Hertz contact theory and the finite element

\begin{tabular}{ccccc}
\hline Hertz & Finite & Finite & Finite & Finite \\
contact & element & element & element & element \\
\hline
\end{tabular}




\begin{tabular}{cccccc}
\hline & theory & DS3mm & DS4mm & DS5mm & DS6mm \\
\hline $\begin{array}{c}\text { Maximum contact stress } \\
(\mathrm{MPa})\end{array}$ & 3292.7 & 3130 & 3126 & 3115 & 3104 \\
\hline
\end{tabular}

Von Mises consider the combined effect of the independent normal stress and shear stress that follow the fourth strength theory. When the equivalent stress reaches a certain value, the point begins to enter the plastic state. The maximum von Mises is $1429 \mathrm{MPa}$ and is located under the raceway surface when the hardened depth is $4 \mathrm{~mm}$, as shown in Fig. 26. The surrounding arc area stress is highly concentrated and easily damaged. S, Tresca distribution is very similar to the von Mises and the maximum value is $1599 \mathrm{MPa}$ under the raceway surface, as shown in Fig. 27.

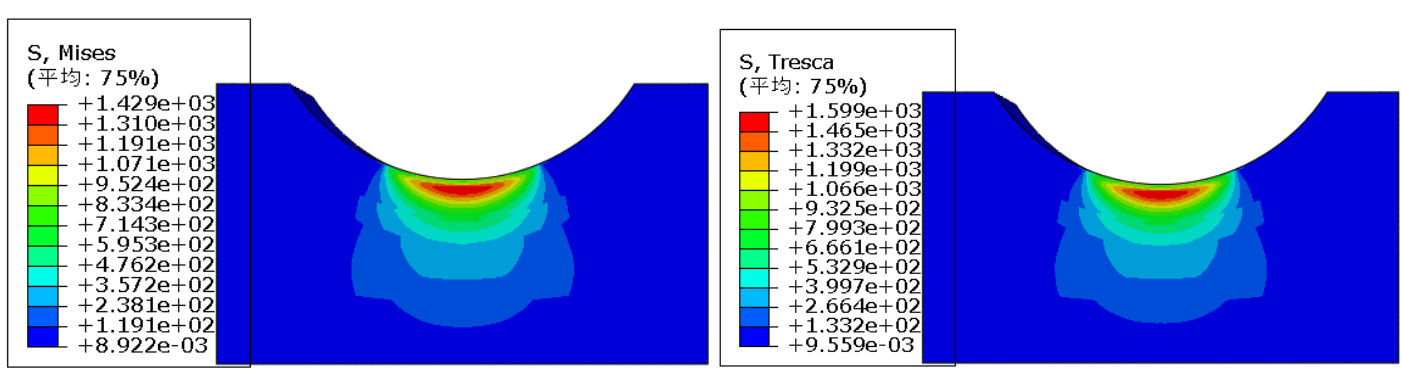

Fig. 26 von Mises of DS $4 \mathrm{~mm}$

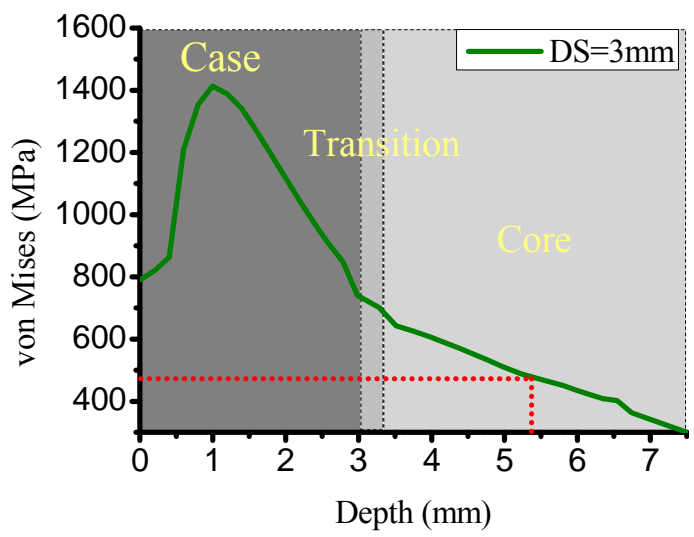

(a)
Fig. $27 \mathrm{~S}$, Tresca of DS $4 \mathrm{~mm}$

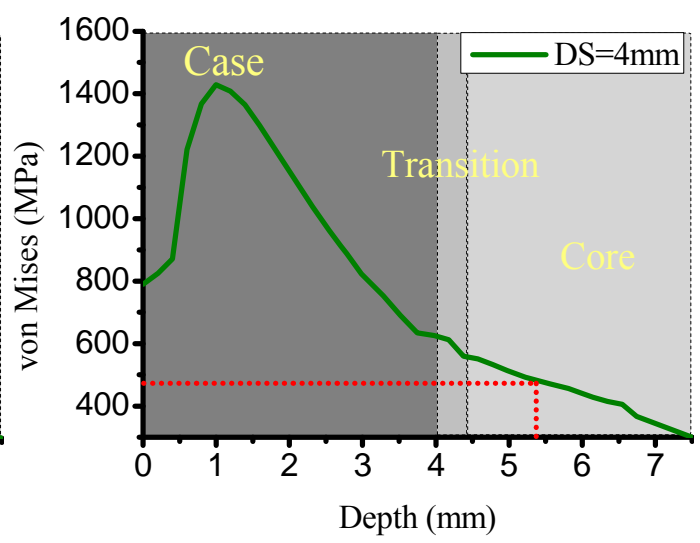

(b) 


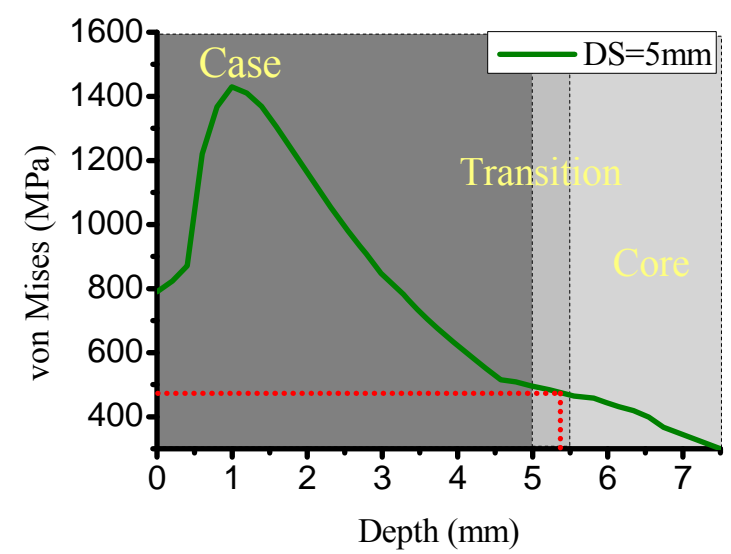

(b)

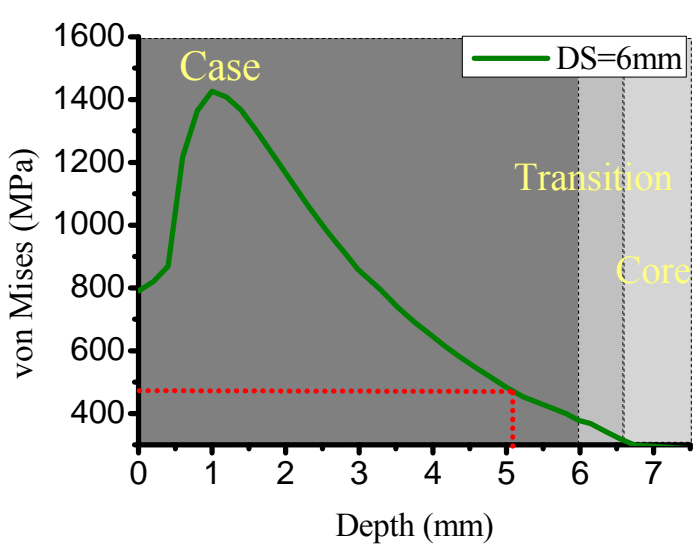

(d)

Fig. 28 Stress path under the raceway surface (a) $\mathrm{DS}=3 \mathrm{~mm}$; (b) $\mathrm{DS}=4 \mathrm{~mm}$; (c) $\mathrm{DS}=5$

$$
\mathrm{mm} ;(\mathrm{d}) \mathrm{DS}=6 \mathrm{~mm}
$$

Von Mises is extracted along the depth direction of the maximum position of the raceway stress, as shown in Fig. 28. The curves of different hardened depths are the same, in that they first rise then fall along the depth direction. The values are different. When the hardened depth is $3 \mathrm{~mm}$, the stress of the core area is bigger than the allowable stress as shown in Fig. 28(a). The core layer will be crushed. The crack will commence in the core layer and expand to the raceway surface, thus causing a large area of peeling. When the hardened depth is $6 \mathrm{~mm}$, the stress of the core area is smaller than the allowable stress, as shown in Fig. 28(d).

The maximum value of the alternating stress has two absolute values of $293 \mathrm{MPa}$ and 293.1 MPa under the raceway surface. The stress of the two parts is almost a symmetrical distribution, as shown in Fig. 29. The stress distributions of different hardened depths are the same and thus not listed one by one. Various stress values differ little among groups in Fig. 30.

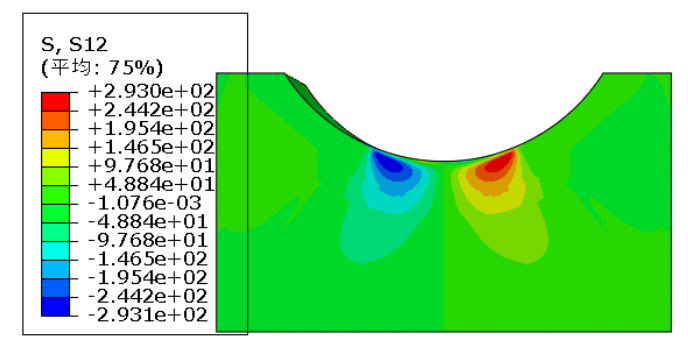

Fig. 29 The alternating stress of DS $4 \mathrm{~mm}$ 


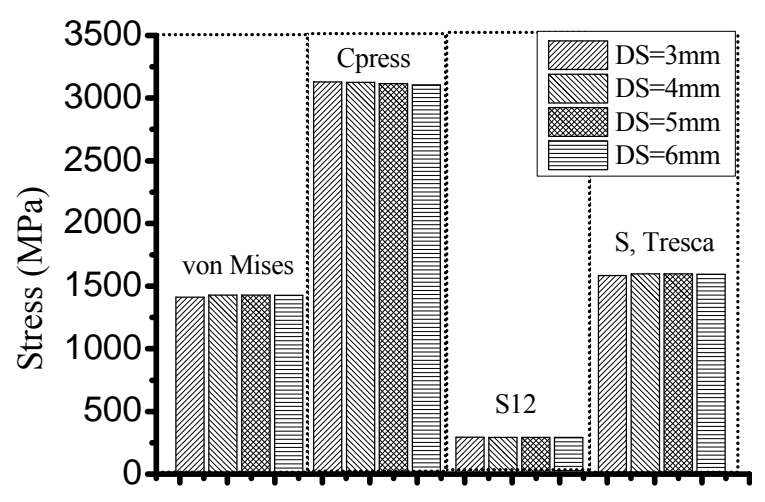

Fig. 30 Various stress of different hardened depth

Maximum shear stress theory (the third strength theory) shows the point will yield when the maximum shear stress reaches a certain value. There are many views on the influence of subsurface stress on rolling contact fatigue. It is generally considered that the maximum static shear stress plays a major role in the plastic deformation of the contact surface. The maximum dynamic shear stress plays a major role in the occurrence and expansion of contact fatigue cracks. The depth of maximum Mises is shallower than the depth of maximum shear stress. It can be seen that plastic deformation and fatigue damage are likely to occur in the vicinity of the position where the maximum static shear stress is generated.

\subsection{Life analysis of local solid model}

Fe-safe is a special software package for structural fatigue analysis, more specifically for analyzing the fatigue life of a yaw bearing. $42 \mathrm{CrMo}$ fatigue data are obtained by the Seeger algorithm combined with ultimate tensile strength and elastic modulus. The $42 \mathrm{CrMo}$ tensile ultimate strength is $1080 \mathrm{MPa}$ and the elastic modulus is $207000 \mathrm{MPa}$. The $\mathrm{S}-\mathrm{N}$ and $\varepsilon-\mathrm{N}$ curves are shown in Fig. 31. The roughness Ra of the yaw bearing raceway surface is $0.25<\mathrm{Ra}<0.6 \mu \mathrm{m}$. The contact load is considered to be a pulsating cycle, as shown in Fig. 32 [32]. The Brown-Miller algorithm is the preferred method recommended by the American Association of automobile manufacturers, since fatigue damage occurs on the plane that experiences the maximum shear stress amplitude. Fatigue damage is the result of the maximum shear 
strain and the co-action of the principal strain on this plane [33].

The Morrow mean stress criterion is used to modify the average stress and strain. It subtracts the average stress per cycle to correct the elastic stress and make the predicted fatigue life closer to the actual fatigue life [34]. Morrow's mean stress-modified Brown-Miller strain-life equation is expressed as equation (15).

$$
\frac{\Delta r_{\max }}{2}+\frac{\Delta \varepsilon_{n}}{2}=c_{1} \frac{\sigma_{f}^{\prime}}{E}\left(2 N_{f}\right)^{b}+c_{2} \varepsilon^{\prime} f^{\left(2 N_{f}\right)^{c}}
$$

where $\Delta r_{\text {max }}$ is the shear strain amplitude $(\mathrm{mm}), \Delta \varepsilon_{n}$ is the principal strain amplitude (MPa), $N_{f}$ is the number of cycles, $\sigma_{f}^{\prime}$ is the fatigue strength coefficient, $c$ is the ductility index, $\varepsilon_{f}^{\prime}$ is the fatigue extension coefficient, and $E$ is Young's modulus (MPa).

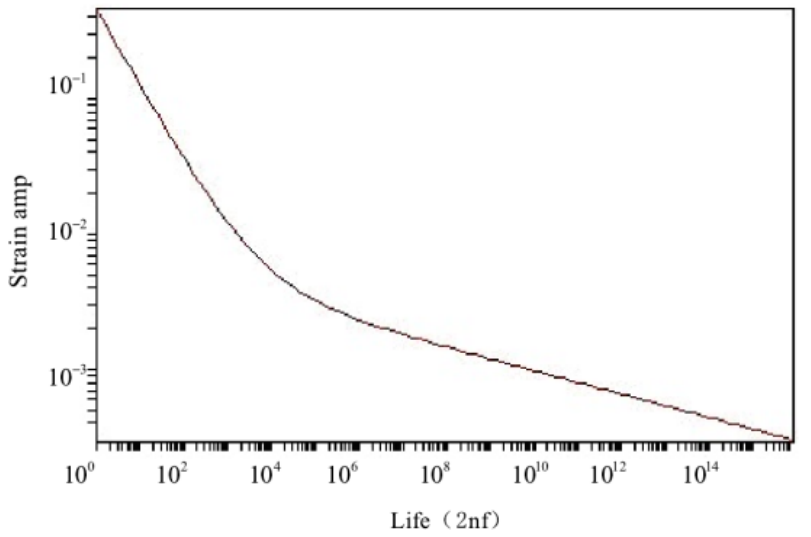

(a)

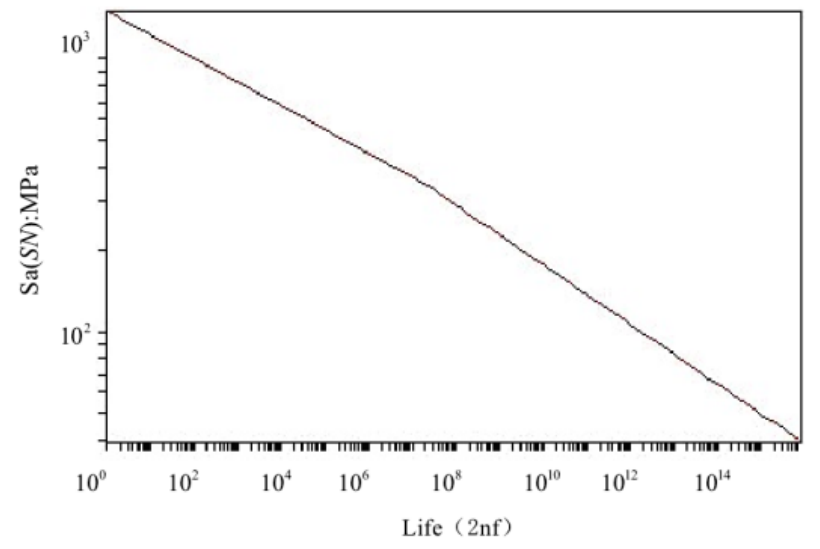

(b)

Fig. 31 (a) 42CrMo S-N curve; (b) 42CrMo $\varepsilon-\mathrm{N}$ curve 


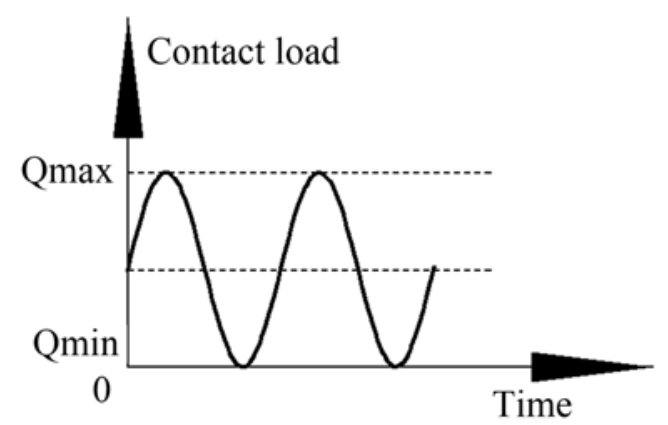

Fig. 32 Load information

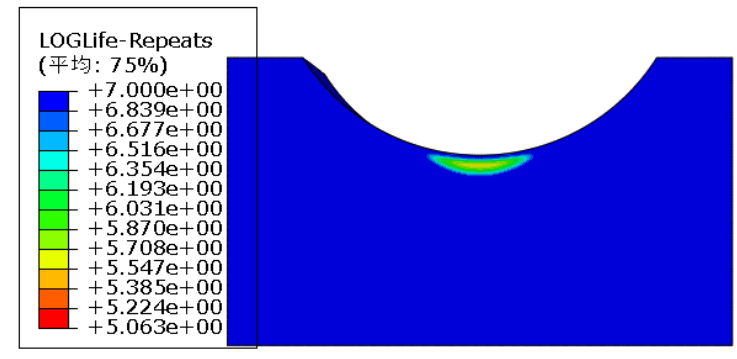

(a)

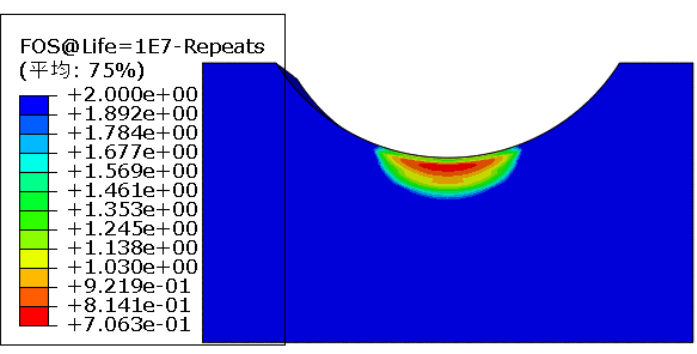

(b)

Fig. 33 Yaw bearing fatigue life of DS 4mm (a) Logarithmic life; (b) Fatigue strength factor

The area with low fatigue life is similar to a von Mises distribution and the minimum value is 5.063 under the raceway surface, as shown in Fig. 33. The cycle number is $10^{5.063}$. Fatigue failure of a yaw bearing occurs in the stress concentrated area. A crack is first generated in this area and then expands. The surface is peeled off, which exacerbates bearing wear and enlarges the damage range. A fatigue strength factor gives a reduction factor for the stress at the target life, which outputs the result of the unit stress. If the value is less than 1 , this indicates that the current stress state multiplied by the fatigue strength factor can reach the target life. If the value is greater than 1 , this indicates that the current stress state is lower than the target life required stress state.

According to the United States. National Renewable Energy Laboratory wind turbine slewing bearing fatigue life theory calculation "Wind turbine design guideline DG03: yaw and pitch rolling bearing life" [20], the basic dynamic axial load rating is as follows:

$$
\mathrm{C}_{\mathrm{a}}=\mathrm{f}(\mathrm{i} \cos \mathrm{a})^{0.7} \mathrm{n}^{2 / 3} \mathrm{D}_{\mathrm{w}} 1.8_{\operatorname{tana}}
$$


where $f$ is the raceway groove curvature radius/ $D, n$ is the ball number, $i$ is the rolling element row, $D_{w}$ is the roller diameter, and $a$ is the contact angle.

The slewing bearing dynamic equivalent axial load rating is as follows:

$$
\mathrm{P}_{\text {ea }}=0.75 \mathrm{~F}_{\mathrm{r}}+\mathrm{F}_{\mathrm{a}}+2 \mathrm{M} / \mathrm{D}_{\mathrm{L}}
$$

The slewing bearing basic rating $L_{10}$ formula (for $10 \mathrm{e} 6$ revolutions) is as follows:

$$
L_{10}=\left(\frac{C_{a}}{P_{e a}}\right)^{3}
$$

The slewing bearing ANSI/ABMA standard modified rating life $L_{n m}$ formula (for 10e6 revolutions) is as follows:

$$
L_{n m}=a_{1} a_{2} a_{3} a_{4} L_{10}
$$

where $a_{1}$ is the life modification factor for reliability (reliability 90\%), $a_{2}$ is the life modification factor for bearing steel or another material, $a_{3}$ is the life modification factor for lubrication, and $a_{4}$ is the life modification factor for a flexible supporting structure.

The final wind turbine slewing bearing fatigue life theory estimate is 2096.875revolutions.

$$
T_{1}=\operatorname{Lnm}^{*} n=134200
$$

The theoretical fatigue life of a yaw bearing is larger than the simulated fatigue life. The fatigue life increases with hardened depth, as shown in Fig. 34. 


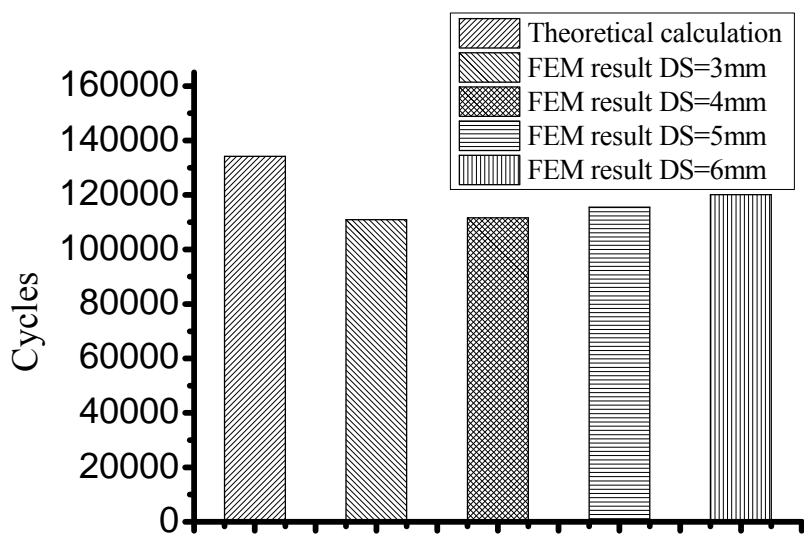

Fig. 34 Theoretical versus simulated fatigue life

\section{Conclusion}

In this paper, analysis of a yaw bearing hardened raceway is carried out. Using a non-linear spring instead of the ball quickly obtained maximum contact load between ball and raceway. The maximum contact load is compared with Hertz contact theory. A strain gauges experiment verifies the whole non-linear spring finite element model. Then a local ball and raceway finite element model is established and the raceway divided into the core layer, transition layer, and the hardened layer. An indentation test and Hertz contact theory are used together to verify the local finite element model with different layers. Stress results of different hardened depths are compared with Hertz contact theory, and fatigue life results compared with the theoretical yaw bearing fatigue life. The following results were forthcoming: 1) The maximum surface contact stress obtained by the finite element method is smaller than the Hertz contact theory. The maximum surface contact stress of different hardened depths is different and the error values small; 2) Stress curve trends extracted path along the position of the maximum von Mises for different hardened depths are the same and the values are small different; 3) The theoretical fatigue life of a yaw bearing is larger than the simulated fatigue life. Also, fatigue life increases with hardened depth.

\section{Acknowledgements}

The authors gratefully acknowledge the support provided by the National Natural Science Foundation of China (51105191, 51375222), the project of Jiangsu provincial 
Six Talent Peaks (GDZB-033), the Shanghai Sailing Program (16YF1408500).

\section{Reference}

[1] Yanshuang W, Jiawei C. Determination of the precise static load-carrying of pitch bearings based on static models considering clearance. Int J Mech Sci 2015; 100:209-215.

[2] Guanci C, Jianmin W. Effects of size and raceway hardness on the fatigue life of large rolling bearing. J Mech Sci Technol 2015; 29: 3873-3883.

[3] Jon P, Mikel A, Ibai C. A new finite element approach for the analysis of slewing bearings in wind turbine generators using superelement techniques. Meccanica 2015; 50: 1623-1633.

[4] Peter G, Miran U, Srečko G. Computational assessment of the allowable static contact loading of a roller-slewing bearing's case-hardened raceway. Int J Mech Sci 2015; 94-95:174-184.

[5] Xuehai G, Xiaodiao H, Hua W, et al. Modelling of ball-raceway contacts in a slewing bearing with non-linear springs. P I Mech Eng C-J Mec 2014; 225 : 827-831.

[6] Josu A, Jon P, Mikel A, et al. Effect of the preload in the general static load-carrying capacity of four-contact-point slewing bearings for wind turbine genegators: theoretical model and finite element calculations. Wind energy 2014; 17: $1605-1621$.

[7] Peter G, Srečko G. Rolling contact fatigue life assessment of induction hardened raceway. Procedia Engineering2014; 74:392-396.

[8] Ludwik K, Marek K, Eugeniusz M. A catalogue capacity of slewing bearings. Mech Mach Theory 2012; 58: 29-45.

[9] Xuehai G, Xiaodiao H, Hongrong J, et al. A rolling contact fatigue reliability evaluation method and its application to a slewing bearing. J Tribol 2012; 134 : 0111011-0111017.

[10] Peter G, Rok P, Srečko G. Computational model for determination of static load 
capacity of three-row roller slewing bearings with arbitrary clearances and predefined raceway deformations. Int J Mech Sci 2013; 73: 82-92.

[11] Rok P, Peter G, Jože F, et al. Fatigue life of double row slewing ball bearing with irregular geometry. Procedia Engineering 2010; 2:1877-1886.

[12] Junbiao L, Pascal O, Hans K, et al. Case depth and static capacity of surface induction-hardened rings. Journal of ASTM International 2009; 6:1-16.

[13] Robert K, Andrej Z, Ivan P. Verification of numerical determination of carrying capacity of large rolling bearings with hardened raceway. Int J Fatigue 2007; 29: 1913-1919.

[14] Mireia O, Xabier S, Jorge D, et al. Design of four contact-point slewing bearing with a new load distribution procedure to account for structural stiffness. J Mech Des 2010; 132: 21-60.

[15] Daidié A, Chaib Z, Ghosn A. 3D simplified finite elements analysis of load and contact angle in a slewing ball bearing. J Mech Des 2008; 8: 0823011-0826018.

[16] Peter G, Rok P, Srečko G. Computational model for determination of static load capacity of three-row roller slewing bearings with arbitrary clearances and predefined raceway deformations. Int J Mech Sci 2013; 73: 82-92.

[17] Peter G, Rok P, Srečko G. Fatigue behaviour of $42 \mathrm{CrMo} 4$ steel under contact loading. Procedia Engineering 2010; 2:1991-1999.

[18] Zaretsky E V, Poplawski J V, Peters S M. Comparison of life theories for rolling-element bearings. Tribol T1996; 39: 237-248.

[19] JB/T 2300-2011. Slewing bearing. In: In: People's Republic of China machinery industry standards, China, 2011.

[20] T. Harris, J. H. Rumbarger, and C.P.Butterfield. National Renewable Energy Laboratory. Technical Report with number NREL/TP-500-42362 Wind turbine design guideline DG03: yaw and pitch rolling bearing life: 2009.

[21] Harris, T. A. (2001), Rolling Bearing Analysis, John Wiley \& Sons, New York.

[22]Ricci M. Static load distribution in ball bearings. Proceedings of the 40th Aeospace Mechanisms Symposium, NASA kennedy Space Center, 2010:12-14.

[23] Lazovic T, Ristivojevic M, Mitrovic R. Mathematical Model of Load Distribution 
in Rolling Bearing. FME Transactions2008; 36: 189-196.

[24] Lina Z. The calculation analysis of the slewing bearing raceway hardened depth. Haerbin bearing2015; 36: 7-9.

[25] Zheng Y. Carrying analysis and optimization of the slewing bearing. Hefei Technology University 2014.

[26] K L. Johnson. Contact mechanics. Cambridge University Press 1985.

[27] Liguang T. Probability Theory and Mathematical Statistics. Hefei: Hefei Technology University Press, 2004.

[28] Glodež S, Potočnik R, Flašker J. Computational model for calculation of static capacity and lifetime of large slewing bearing's raceway. Mech Mach Theory 2012; 47: $16-30$.

[29] M. Bauccio, ASM Metals Reference Book, ASM International, 1993.

[30] Information on http://www.fatiguecalculator.com (data retrieved from SAE J1099 report).

[31] Zhiqiang H. Design of Ball Bearings. Beijing: Mechanical Industry Press 2003.

[32] Rok P, Jože F, Srečko G. Fatigue analysis of large slewing bearing using strain-life approach.Icf12 Ottwa 2013; 5: 3891-3898.

[33] FE-SAFE In. FE-SAFE User's Manual, 2011, Dassault Systemes; France.

[34] Morrow J. Fatigue Design Handbook. Society of Automotive Engineers1968, 4 (3.2)21-29. 